\title{
LA TRIBUTACIÓN AMBIENTAL COMO INSTRUMENTO DE POLÍTICA PÚBLICA EN EL ECUADOR.
}

\section{ENVIRONMENTAL TAXATION AS AN INSTRUMENT OF PUBLIC POLICY IN ECUADOR.}

\section{Gabriela Judith Valdivieso Ortega, PhD.}

Doctora en Derecho (Ecuador).

Docente de la Universidad Técnica Particular de Loja a cargo del componente académico derecho tributario, Ecuador. gjvaldivieso@utpl.edu.ec

\section{ARTÍCULO DE REFLEXIÓN}

Recibido: 18 de octubre de 2017

Aceptado: 21 de marzo de 2018

\section{RESUMEN}

La Constitución del Ecuador contempla dentro de las garantías constitucionales a las políticas públicas, siendo parte de estas últimas la política tributaria. Dentro de los objetivos de la política tributaria de nuestro país se encuentra la protección del medio ambiente sano. Por otra parte, a pesar de la discusión doctrinaria, los autores tributarios aceptan de modo general los fines extra fiscales de los tributos, entre los que cabe la utilización de los mismos como instrumentos de política pública tributaria. En este trabajo analizaremos entonces en base a la doctrina relevante y a la normativa ecuatoriana si cabe o no la utilización de tributos como mecanismos de política pública para la protección del derecho a un medio ambiente sano en nuestro país.

Palabras clave: políticas, públicas, garantías constitucionales, tributos, extra-fiscal. 


\section{ABSTRACT}

The Constitution of the Republic of Ecuador contains in its constitutional guarantees the public policies, where the taxation policy is included. The objectives of the taxation policy of Ecuador also includes the protection of the natural environment. Despite the doctrinarian discussion, tributary authors generally accept extra-fiscal purposes of taxation, on which proceeds the use of taxation as an instrument of public policy. The following study analyzes relevant doctrine and the Ecuadorian normative to argue whether proceeds or not using taxes as mechanisms of public policy to protect the right to a healthy environment in Ecuador.

Keywords: public, policies, constitutional guarantees, taxes, extra-fiscal

\section{INTRODUCCIÓN}

En la actualidad, debido al crecimiento del intervencionismo del Estado y al incremento de la complejidad de los problemas públicos no debe resultar extraño que el Estado haga uso del sistema tributario para llevar adelante algunas políticas públicas, más aún en el caso ecuatoriano, donde son auténticas garantías constitucionales. $Y$ es que, cada vez es más común encontrar a nivel mundial tributos que tienen una finalidad, al menos principal, distinta a la recaudatoria, plasmados en distintas leyes, pues de lo contrario se violentaría los principios de legalidad y de reserva de ley. Sin embargo, sería interesante que exista detrás una política pública perfectamente estructurada para que haya una mejor congruencia entre las diferentes instituciones tributarias utilizadas y los fines que persiguen.

En este artículo se aborda específicamente la utilización de los tributos, como medios o mecanismos que deben ser considerados dentro de las políticas públicas para proteger el derecho-deber a un medio ambiente sano en el Ecuador, analizando aquellas políticas que se consideran factibles, tomando en cuenta sobre todo los objetivos de las mismas y su relación con la tributación.

Es así que hemos estructurado este artículo en tres partes. En la primera parte, revisaremos algunas de las políticas públicas en el Ecuador y la protección jurídica que se le ha otorgado al medio ambiente; la segunda parte estará dedicada a la revisión de los tributos, sus 
finalidades y los diferentes tipos existentes; y, la última parte se dedicará al análisis de los tributos ambientales y el beneficio de su utilización como mecanismos de política pública.

\section{REVISIÓN TEÓRICA}

\section{Las políticas públicas en el Ecuador.}

\section{Las políticas públicas como garantías constitucionales.}

En la Constitución de la República del Ecuador, dentro del Título III, denominado Garantías Constitucionales, se encuentran establecidas tres clases de garantías constitucionales: las garantías normativas, las garantías jurisdiccionales y políticas públicas. Sin embargo, sería en vano negar que, en criterio de la autora, la división de poderes, la acción ciudadana, la supremacía de la Constitución, el deber de aplicar la interpretación que más favorezca a la vigencia de los derechos constitucionales, entre otras, constituyen también garantías constitucionales. Pero más allá de la discusión que podría iniciarse al respecto y que no es punto central de este análisis, parte de una verdad fundamental que no admite discusión y esta es que: Las Políticas Públicas en el Ecuador son auténticas garantías de carácter constitucional. (Constitución de la República del Ecuador, 2008).

Ahora bien, no se precisará en la revisión de todas estas garantías mencionadas en el párrafo anterior, sino que, por la relación con el tema, por lo que se hará énfasis en el estudio de las políticas públicas; y, para esto se iniciará señalando que, el desarrollo doctrinario respecto a las mismas como garantías constitucionales es incipiente o nulo, lo cual se cree que se debe, al menos en cierta medida, a que solamente la Carta Magna de nuestro país las contempla como tales.

Sin embargo, de lo mencionado, se puede aplicar a las políticas públicas, conceptos amplios y actuales en relación a las garantías de carácter constitucional, como el vertido por Storini (2008) por ejemplo, quien las define como mecanismos de protección imprescindibles para la real eficacia jurídica de los derechos fundamentales.

Se debe mencionar, además, que la preocupación por el análisis de las políticas públicas se dio a partir de la segunda guerra mundial; $y$, que los estudios en relación a las mismas se iniciaron en Estados Unidos de Norte América, específicamente en la década de los 
cincuenta, extendiéndose a Europa en los años sesenta y al mundo hispano a partir de los años noventa, con la traducción al castellano de libros como Politiques Publiques (Ordóñez, 2013).

En la actualidad, y sobre todo a partir de los últimos treinta años, el tema de las políticas públicas ha adquirido cada vez más importancia, debido al incremento de la cantidad y complejidad de los problemas que afectan a los diferentes estados, siendo inminente la utilización de herramientas que permitan desarrollar y aplicar políticas basadas en el conocimiento y ya no en el empirismo como se lo hacía en un inicio.

En el caso específico del Ecuador se puede considerar que las políticas públicas han alcanzado una significativa relevancia a partir de la vigencia de la Constitución 2008. Primero, porque como se puede señalar, este cuerpo normativo las estatuye claramente como garantías constitucionales, y por lo tanto como medios para lograr la plena efectividad de los derechos constitucionales; y, segundo, porque la Ley está caracterizada por un gran intervencionismo estatal, consagrándonos expresamente como un estado social, es decir, un estado de carácter prestacional que debe buscar el bienestar común mediante todos los mecanismos con los que cuenta.

El tema de las políticas públicas a pesar de la importancia que ha adquirido, no es una cuestión sencilla, pues se las ha definido de muy diversas maneras dependiendo desde el punto de vista desde el que se las analiza, sin embargo, de modo general, son: "la concreción del Estado en acción frente a los problemas de la sociedad" (Valdivieso, 2016, p. 50) Es decir, “(...) es todo aquello que los gobiernos deciden hacer o no hacer. (Fernández, 2001, p.464)

En cambio, sin duda estos conceptos no abarcan al menos en su totalidad la definición de política pública en el caso ecuatoriano, pues si bien no podemos soslayar que las mismas deben utilizarse como mecanismos para hacer frente a los diversos problemas por los que atraviesa el país, son garantías constitucionales, y por lo tanto deben ser utilizadas para lograr la plena eficacia de los derechos de carácter constitucional. 
Con la finalidad de aclarar este último punto, se continuará entonces con el análisis de las políticas públicas en la Constitución de la República y se advierte que dentro del título III "Garantías Constitucionales", se señala respecto a las mismas lo siguiente:

La formulación, ejecución, evaluación y control de las políticas públicas y servicios públicos que garanticen los derechos reconocidos por la Constitución, se regularán de acuerdo con lo siguiente:

1. Las políticas públicas y la prestación de bienes y servicios públicos se orientarán a hacer efectivos el buen vivir y todos los derechos, y se formularán a partir del principio de solidaridad.

2. Sin perjuicio de la prevalencia del interés general sobre el interés particular, cuando los efectos de la ejecución de las políticas públicas o prestación de bienes o servicios públicos vulneren o amenacen con vulnerar derechos constitucionales, la política o prestación deberá reformularse o se adoptarán medidas alternativas que concilien los derechos en conflicto.

3. El Estado garantizará la distribución equitativa y solidaria del presupuesto para la ejecución de las políticas públicas y la prestación de bienes y servicios públicos. En la formulación, ejecución, evaluación y control de las políticas públicas y servicios públicos se garantizará la participación de las personas, comunidades, pueblos y nacionalidades. (Constitución de la República del Ecuador, 2008)

Es decir, la Ley no solamente estatuye a las políticas públicas como garantías constitucionales, sino que señala claramente que su formulación, ejecución, evaluación y control debe regularse atendiendo, en lo fundamental, a que su orientación esté dirigida a hacer efectivo el buen vivir y todos los derechos, considerando como base el principio de solidaridad. Tanto es así que en el caso de que los efectos de las mismas violenten o amenacen con vulnerar derechos constitucionales tienen que ser reformadas, siendo además obligaciones del Estado distribuir de manera equitativa el presupuesto para su formulación y garantizar en la elaboración de dichas políticas la participación de las personas, comunidades, pueblos y nacionalidades. (Constitución de la República del Ecuador, 2008) 
Reafirma aún más la importancia de las políticas públicas en Ecuador, lo establecido en nuestro texto constitucional, en el sentido de que para la consecución del buen vivir el Estado tiene como obligación "Generar y ejecutar las políticas públicas, y controlar y sancionar su incumplimiento." (Constitución de la República del Ecuador, 2008). Es decir, el Estado tiene el deber no solo de crear políticas públicas, sino de hacerlas cumplir y sancionar a quien no lo haga, con la finalidad de alcanzar el sumak kawsay.

Para finalizar este punto es imperioso señalar que, en el caso ecuatoriano, las políticas públicas están inminentemente relacionadas con el Plan de Desarrollo, pues la Carta Magna establece que éste "es el instrumento al que se sujetarán las políticas, programas y proyectos públicos (...)” (Constitución de la República del Ecuador, 2008). No obstante, el Plan Nacional de Desarrollo el que debe ir ajustándose a las políticas públicas que se inserten, pues éstas se crean conforme a los problemas que hay que afrontar y a los derechos que se debe efectivizar, de acuerdo a determinado momento y de acuerdo a circunstancias imprevistas, por lo que pueden ser sumamente cambiantes, es así, que en este Plan deberían constar solamente cuestiones y directrices generales.

\section{Política económica, política fiscal, política tributaria.}

La política económica, es una de las políticas públicas más importantes con las que cuentan los diferentes países como una herramienta de intervención del Estado en la economía, la cual ha adquirido una gran relevancia en el Ecuador en los últimos años, pues como se puede mencionar en líneas precedentes, por ser a partir de la vigencia de la Constitución de 2008 un Estado con un alto carácter intervencionista. La política económica como lo señala Vicuña (2015):

Busca crear condiciones necesarias para aprovechar la capacidad productiva de los países en forma eficiente, con alta productividad, en búsqueda de incrementar sostenidamente la producción para lograr crecimiento económico y progreso social; esto es, elevar las condiciones de vida y la redistribución de la riqueza. (p. 1)

La orientación que debe tener esta política pública en el Ecuador se encuentra establecida en el artículo 283 de la Constitución, el cual señala que: 
El sistema económico es social y solidario; reconoce al ser humano como sujeto y fin; propende a una relación dinámica y equilibrada entre sociedad, Estado y mercado, en armonía con la naturaleza; y tiene por objetivo garantizar la producción y reproducción de las condiciones materiales e inmateriales que posibiliten el buen vivir. (Constitución de la República del Ecuador, 2008).

En el mismo sentido el artículo 284 ibídem, contempla entre los objetivos de la política económica en el Ecuador, el de: "Impulsar un consumo social y ambientalmente responsable." (Constitución de la República del Ecuador, 2008).

Ahora bien, la política económica se encuentra instrumentada mediante otras políticas microeconómicas y macroeconómicas, siendo parte de estas últimas la política fiscal, la cual ha sido definida de modo general, como aquella política pública: “(...) encargada de obtener ingresos tributarios y no tributarios para financiar los gastos públicos" (Plazas, 2006, p. 279); y cuyos objetivos en el caso ecuatoriano se encuentran contemplados en el artículo 285 de la Constitución, entre los cuales destacamos por la relación con el tema el siguiente "La generación de incentivos para la inversión de los diferentes sectores de la economía y para la producción de bienes y servicios, socialmente deseables y ambientalmente aceptables." (Constitución de la República del Ecuador, 2008)

Algunos autores se refieren a la política fiscal como sinónimo de la política tributaria, a pesar de que no son exactamente lo mismo, pues la política fiscal es más amplia. La política tributaria se preocupa solamente de aquellos ingresos ordinarios del Estado llamados tributos; y, la Ley, señala que ésta: "promoverá la redistribución y estimulará el empleo, la producción de bienes y servicios, y conductas ecológicas, sociales y económicas responsables. (Constitución de la República del Ecuador, 2008).

Para concluir este punto entonces señalando que, la política económica, la política fiscal y la política tributaria son políticas públicas en el Ecuador; y, que todas ellas tienen dentro de sus objetivos o finalidades proteger el medio ambiente.

\section{La política ambiental.}

Existen ciertos problemas como el medioambiental, que han adquirido relevancia a nivel mundial; $y$, que a pesar de que deben ser afrontados por los estados, existe una importante 
base de normativa internacional y sustento teórico a tomar en cuenta al formular las políticas públicas ambientales en el Ecuador.

Las políticas de carácter ambiental de modo general se han configurado con el transcurrir del tiempo, adquiriendo mayor relevancia en los últimos sesenta años; y, han llegado a establecerse tres generaciones de las mismas. La primera generación de éstas políticas tuvo como punto de partida la Conferencia Mundial sobre el Medio Ambiente Humano, celebrada en Estocolmo en el año de 1972; la segunda generación de las políticas públicas medioambientales, se dio durante los años ochenta y noventa, y se basó casi en su totalidad en la primera generación, no obstante, se tomaron en cuenta ciertos desaciertos que se intentaron corregir; y, la tercera generación de las políticas en cuestión, que es frente a la que nos encontramos actualmente se ha desarrollado fundamentalmente con base en los informes de la Organización de Cooperación y Desarrollo Económico, en adelante OCDE (Figueroa, 2000).

En tal sentido, se establece un análisis detallado de las tres generaciones de políticas públicas, puesto que si bien a través de las mismas se han elaborado una serie de principios y directrices que rigen a nivel internacional, son los Estados los que a través de la política pública ambiental interna, pueden hacer de estos buenos deseos una realidad social.

En el caso ecuatoriano se debe partir resaltando la importancia que el Constituyente dio a la parte ambiental a lo largo del texto constitucional a través de una serie de disposiciones, partiendo desde su preámbulo, el cual señala expresamente que el pueblo soberano del Ecuador ha decidido construir: "Una nueva forma de convivencia ciudadana, en diversidad y armonía con la naturaleza, para alcanzar el buen vivir, el sumak kawsay" (Constitución de la República del Ecuador, 2008); considerando que como bien lo señala Amaya (2010) éste:

(...) incorpora mucho más allá de un simple mandato específico, los fines hacia los cuales tiende el ordenamiento jurídico; los principios que inspiraron al constituyente para diseñar de una determinada manera la estructura fundamental del Estado; la motivación política de toda la normatividad; así como los valores que esa Constitución aspira a realizar y que trascienden la pura literalidad de sus artículos. (p.134) 
Es decir, que la Constitución destaca desde un inicio la importancia de la naturaleza, la cual está estrechamente ligada con el medio ambiente, estatuyéndola inclusive posteriormente como sujeto de derecho; al igual que por otra parte reafirma la relación que existe entre ésta y el ser humano.

En cuanto a la política ambiental específicamente, la Ley hace referencia a la misma en varios de sus artículos, no obstante, la desarrolla en el numeral 2 del artículo 395 al establecer lo siguiente: "Las políticas de gestión ambiental se aplicarán de manera transversal y serán de obligatorio cumplimiento por parte del Estado en todos sus niveles y por todas las personas naturales o jurídicas en el territorio nacional." (Constitución de la República del Ecuador, 2008).

En opinión de la autora de este artículo, considera la importancia de la política pública ambiental en el Ecuador; y, a pesar de que no se establece específicamente los objetivos de la misma, considerando la naturaleza propia de la misma y lo establecido en el artículo 85 de nuestra Constitución, en el sentido de que todas las políticas públicas deben estar orientadas a hacer efectivos el buen vivir y todos los derechos, podemos señalar que entre las finalidades de la misma se encuentra sin duda la protección al medio ambiente. (Constitución del Ecuador, 2008)

El derecho - deber a un medio ambiente sano en el Ecuador.

Sin duda, para analizar correctamente la tributación ambiental como mecanismo de las políticas públicas antes analizadas, es necesario que se tenga claro la protección jurídica otorgada al medio ambiente por nuestro texto constitucional, para lo cual no se profundizará en el estudio de este bien tan preciado desde la perspectiva biológica.

Se parte de señalar entonces que nuestra Ley de Leyes reconoce expresamente "(...) el derecho de la población a vivir en un ambiente sano y ecológicamente equilibrado, que garantice la sostenibilidad y el buen vivir, sumak kawsay." (Constitución de la República del Ecuador). Es decir, el derecho a un medio ambiente sano es un derecho constitucional en nuestro país. Lo cual adquiere fuerza cuando nuestro mismo texto constitucional declara de interés público “(...) la preservación del ambiente, la conservación de los ecosistemas, la 
biodiversidad y la integridad del patrimonio genético del país, la prevención del daño ambiental y la recuperación de los espacios naturales degradados (Constitución de la República del Ecuador, 2008).

Por otra parte, la Carta Magna estatuye en el artículo 86 numeral 1 entre los deberes y responsabilidades de los ecuatorianos el de: "6. Respetar los derechos de la naturaleza, preservar un ambiente sano y utilizar los recursos naturales de modo racional, sustentable y sostenible" Constitución de la República del Ecuador, 2008). Entonces, se puede señalar que la Constitución, establece que los ecuatorianos estan obligados a cuidar el medio ambiente, coadyuvando su protección al establecerlo como un deber.

En este punto se puede señalar, que más allá de un acuerdo o desacuerdo, el espíritu vanguardista del constituyente, con la finalidad de proteger el medio ambiente y otros bienes que son parte de la naturaleza, éste inclusive estatuyó a la naturaleza como sujeto de derecho al establecer lo siguiente en los artículos de la misma 71 y 72 , respectivamente.

La naturaleza o Pacha Mama: (...) tiene derecho a que se respete integralmente su existencia y el mantenimiento y regeneración de sus ciclos vitales, estructura, funciones y procesos evolutivos; y, de igual modo, tiene derecho a la restauración, que es (...) independiente de la obligación que tiene el Estado y las personas naturales o jurídicas de indemnizar a los individuos y colectivos que dependan de los sistemas naturales afectados (Constitución de la República del Ecuador, 2008).

Se concluye afirmando que en el Ecuador el medio ambiente sano ha sido reconocido y establecido como un derecho-deber.

\section{Instrumentos económicos de protección ambiental.}

Instrumentos económico fiscales.

La OCDE estableció en el año 1972 el principio quien contamina paga, según el cual, el responsable de la contaminación debe asumir los costos ocasionados por la misma. En base a ésta directriz se emitieron una serie de recomendaciones, culminado con la 
Recomendación del Consejo sobre el uso de instrumentos económicos en la política ambiental OCDE (1991)), a la cual es especial referencia por la relación con el tema

La mencionada recomendación propone expresamente algunos instrumentos económicos tales como, cargas por emisión de contaminación al aire, agua, suelo o la generación de ruido, los permisos comercializables, los estímulos de cumplimiento, las multas, los bonos de ejecución, los tributos, la compensación de daños, entre otros.

La mencionada recomendación va dirigida a la utilización de esta clase de mecanismos en la política ambiental, por la tanto se considera que la gran mayoría de estos instrumentos pueden ser aplicados como instrumentos de las otras políticas públicas analizadas, pues todas ellas tienen una esencia económica importante (OCDE, 2016).

Reafirma lo mencionado que un año después, en el principio 16 de la Declaración de Río (1992) se estableció que:

Las autoridades nacionales deberán procurar fomentar la internalización de los costos ambientales y el uso de instrumentos económicos, teniendo en consideración el criterio de que el que contamina debe, en principio, cargar con los costos de contaminación, teniendo debidamente en cuenta el interés púbico y sin distorsionar el comercio ni las inversiones internacionales.

Como se puede advertir, este principio ya no hace referencia específica a la política ambiental, sino a la obligación de las autoridades nacionales de hacer cumplir el principio quien contamina paga, considerando para ello el interés público, el comercio y las inversiones, para lo cual el Estado puede valerse de todas sus políticas públicas.

Es así que a partir de los noventa, aumenta el protagonismo de los instrumentos económico como medios para proteger el medio ambiente. Sin embargo, con ello surgen nuevos horizontes de debate respecto a la utilización de ciertos instrumentos económicos frente a otros, pues el Estado ha actuado en este campo generalmente a través de políticas públicas de regulación directa o de la utilización de instrumentos de mercado. Sin embargo, estos últimos ya han sido enérgicamente criticados ya que los mismos son compatibles solamente con un mercado perfectamente competitivo en el que los costos de transacción deben ser nulos, lo cual es irreal e imposible (Valdivieso, 2016). 
Dentro de los mecanismos de regulación directa se encuentran los instrumentos económico fiscales, de los que son parte los tributos; y, que han sido definidos como "aquellos que intentan cambiar la estructura de costos y beneficios percibidos por productores y consumidores; $y$, por tanto, tienden a modificar las conductas predominantes de producción y consumo en beneficio del medio ambiente" (Figueroa, 2000, p.46).

Lo que ocurre es que los costos ambientales son costos sociales negativos (externalidades negativas), los cuales deben ser introducidos en el mercado con la finalidad de que no sean asumidos por la sociedad en general, para lo cual son muy útiles los instrumentos económico fiscales; ya que, como se indica en el párrafo precedente tienden a modificar ciertas conductas contaminantes con base en costos y beneficios, que perjudican o benefician, respectivamente a productores y consumidores.

No obstante, la cuestión no es tan sencilla, pues para aplicar este tipo de instrumentos es necesario tener una medición al menos aproximada del valor de los bienes ambientales afectados, o del nivel de contaminación producido por cierta actividad, por ejemplo, lo cual no es muy factible sobre todo en los países en vías de desarrollo.

Sin embargo, a pesar de lo mencionado, se debe mencionar que el uso de tributos con la finalidad de proteger el medio ambiente; ya, ha sido aplicada, entre otros, en países como: Bolivia, Cuba, Chile, Honduras México o Panamá, y sin duda Ecuador, a los cuales se hace referencia por la cercanía con nuestro país (Valdivieso, 2016).

No obstante, cabe resaltar al respecto que, si bien se ha estatuido el uso de estos instrumentos económico fiscales para preservar el medio ambiente, se lo ha hecho a través de normas, esto debido a que los tributos son obligaciones ex lege y de no utilizar este mecanismo, se rompería con principios fundamentales en materia tributaria como lo son el principio de legalidad y el principio de reserva de ley. En cambio, en el caso ecuatoriano al menos, es evidente que la serie de tributos que han sido establecidos con la finalidad de proteger este bien fundamental, no tienen detrás una política pública claramente desarrollada y con objetivos específicos. 


\section{Los Tributos.}

\section{Concepto.}

Es importante mencionar, que dentro de la normativa ecuatoriana no existe un concepto de tributo, sin embargo, este instituto en torno al cual ha gira todo el derecho tributario, ha sido ampliamente estudiado por los diferentes autores, con algunas variaciones, que demuestran en algunos casos un acoplamiento de ciertas instituciones a las condiciones actuales, mientras que, en otros se mantiene una definición rígida, considerándolo una prestación exigida por el Estado con la finalidad de obtener ingresos.

Así por ejemplo Aizega (2001, p.61) intenta proponer una definición de tributo afirmando que éstos "(...) tienen tres características: son debidas a un ente público, encuentran su fundamento en el poder de imperio del Estado y tienen por finalidad, allegar los medios necesarios para las necesidades financieras del mismo". Es decir, bajo la concepción de este autor la finalidad exclusiva de los tributos es obtener ingresos para cubrir el gasto público o cualquier otra necesidad de carácter económico.

Por otra parte, Queralt (2001, pp. 28 y 29), define a este instituto de la siguiente manera: "El tributo es un instituto jurídico que consiste en una prestación pecuniaria exigida por una Administración Pública como consecuencia de la realización del supuesto de hecho al que la ley vincula el deber de contribuir, con el fin primordial de obtener los ingresos necesarios para el sostenimiento de los gastos públicos" (pp. 28-29).

Al respecto, a pesar de que la autora de esta investigación, no concuerda en que el fin principal de los tributos es el de obtener ingresos, pues este objetivo puede convertirse en secundario; se considera que el criterio de este autor es más acorde a la realidad inclusive normativa actual, pues la extra fiscalidad de los tributos, la cual a continuación, ha sido aceptada casi de modo general. 


\section{Clases de tributos.}

El Código Tributario ecuatoriano señala en el artículo 1 lo siguiente:" (...) entiéndase por tributos los impuestos, las tasas y las contribuciones especiales o de mejora" (Código Tributario, 2005). Es decir, que establece una categorización de los tributos en el país, cuyos conceptos no son desarrollados posteriormente, lo cual se debe a una deficiencia de técnica legislativa, pues los conceptos claros de instituciones fundamentales dan mayor certeza al derecho.

Ahora bien, la doctrina clásica clasifica de modo general a los tributos en base a los tipos de necesidades del Estado que satisfacen. Para Giannini por ejemplo, si se trata de necesidades colectivas, éstas deben ser financiadas mediante impuestos; mientras que cuando se trata de necesidades públicas, el Estado debe financiarlas a través del cobro de contribuciones; $y$, en el caso de que se trata de satisfacer necesidades de interés general, a las que el autor define como la sumatoria de varias decisiones privadas, debido a que se da origen a la prestación de un servicio, lo que debe cobrarse son tasas.

Sin decir que esta categorización es errónea, se prefiere seguir la clasificación propuesta por Ataliba que divide a los tributos en vinculados y no vinculados. En los tributos vinculados el hecho generador será siempre o al menos estará vinculado con una actuación estatal referida al obligado; mientras que, en los tributos no vinculados el hecho imponible está libre de cualquier actividad estatal. Entonces, si se sigue esta clasificación los impuestos son tributos no vinculados. Mientras que las tasas y las contribuciones son de carácter vinculado. Las tasas y las contribuciones se diferencian en cambio, debido a que en estas últimas rige el denominado principio de beneficio.

Fines extra fiscales de los tributos en el Ecuador.

El uso de tributos con fines distintos a la obtención de ingresos para el Estado (Fines extrafiscales), ha sido estudiada por la doctrina desde hace mucho tiempo atrás, enfocándose especialmente en la finalidad de los tributos como instrumentos de política económica. No obstante, se considera que sin duda éstos pueden convertirse en 
mecanismos de otras políticas públicas, siempre y cuando los objetivos que se pretendan con los mismos sean constitucionalmente permitidos.

Reafirme lo señalado en el párrafo anterior, lo mencionado por (Baldo, 2000) quien afirma que: "(...) no es posible estar al margen y no considerar al tributo como una posibilidad para cumplir el abanico de objetivos que dispone el poder público mediante las políticas públicas" (p.33). Es decir, es aceptado por la doctrina que cabe la utilización de tributos como instrumentos de política pública en general.

Esto adquiere una importancia especial y sumamente relevante en el caso ecuatoriano, donde las políticas públicas son garantías constitucionales, es decir, no están encaminadas solamente a solventar los diferentes problemas públicos, o a cumplir con los objetivos que se ha establecido en la norma, sino a hacer efectivos los derechos constitucionales, entre los cuales se encuentra el derecho a un medio ambiente sano. Ahora bien, a pesar de lo señalado, existe un debate doctrinario latente, en el sentido de si los tributos pueden tener un fin principal distinto a la obtención de recursos o si este nuevo objetivo solamente puede ser secundario.

Dentro del primer grupo se encuentra, por ejemplo, a Ríos Granados (2005), quien menciona que el fin principal de los tributos debe ser allegar recursos al Estado y que las finalidades extra fiscales de los mismos pueden ser solamente secundarias; mientras que, Fonrouge (1984) afirma que no se debe considerar como un elemento característico del tributo, la finalidad exclusiva de obtener ingresos para financiar sus necesidades, a lo que agrega que en el Estado moderno los tributos pueden tener finalidades preponderantemente o exclusivamente de orden extra fiscal.

Los tributos pueden tener como objetivo principal tanto el fin recaudatorio, como otro fin constitucionalmente protegido, así, por ejemplo, ser instrumentos de política pública para proteger el medio ambiente, en el caso ecuatoriano, no obstante, la obtención de ingresos debe estar siempre presente, pues de lo contrario se estaría frente a cualquiera otra institución, pero no a un tributo. 


\section{Los tributos ambientales.}

\section{Concepto y problemática.}

Los tributos ambientales tienen su origen en los postulados de economía de bienestar basados en el concepto de externalidad, escritos por el economista Arthur Cecil Pigou (Barbe, 1996, p.448)., en los años veinte del siglo anterior; y, aunque el autor se ha referido principalmente a los impuestos, consideramos que este es el origen de todos los tributos de carácter ambiental.

Dentro de la normativa ecuatoriana no existe un concepto de tributo y menos aún de tributo ambiental. No obstante, por ejemplo, el Código Tributario Ambiental para América Latina, en el artículo primero señala que:

Tributos medioambientales son aquellos impuestos, tasas y contribuciones especiales cuyo objeto imponible esté constituido por actos o hechos que inciden negativamente sobre el medio ambiente o que provocan una actuación pública de tutela medioambiental. También tendrán la consideración de tributos medioambientales aquellas prestaciones pecuniarias coactivas de carácter público que presenten rasgos comunes a varias de las categorías tributarias definidas en el artículo 26, párrafo primero, de esta Ley. (Modelo de Código Tributario Ambiental para América Latina, 2003).

Entonces, los tributos medioambientales no constituyen una especie tributaria distinta, sino que podrían identificarse con cualquiera de las tres especies de tributos antes analizadas.

Algunos autores, debido a que se ha utilizado erróneamente como sinónimos tributo e impuesto, sin considerar que estos últimos son solamente una especie de los primeros han elaborado algunos conceptos de tributos ambiental como el siguiente: "impuestos ambientales son aquellos que recaen sobre bienes o servicios contaminantes" (Oliva, 2011, p.17). 
Por su parte Arnaldo (2007) en cambio define a los impuestos ambientales tomando en cuenta las características de los mismos de la siguiente manera: “(...) son una contribución obligatoria, que apunta al cambio de la conducta de aquellos enfrentados al tributo a fin de incorporar en todo o en parte los efectos negativos hacia el ambiente en los costos del contaminador" (p.124). Se concuerda con esta definición en el sentido de que, quizá, el fin principal de los tributos ambientales es lograr un cambio de conducta de los agentes contaminantes a favor de medio ambiente.

Ahora bien, a pesar de que los tributos ambientales han sido aceptados y utilizados como instrumentos para proteger el medio ambiente, han existido dos puntos principales de discusión respecto a los mismos.

La principal crítica que enfrentan estos tributos es que con los mismos se pretende de modo general, que el costo de las externalidades negativas en desmedro del medio ambiente que se originan por ciertas actividades sobre todo de carácter económico, sean asumidas por el productor e inclusive en parte por el consumidor, con la finalidad de evitar el costo social que derivaría, convirtiéndose en una especie de licencias o permisos para contaminar, pues el contaminador simplemente asumiría el valor de los tributos establecidos.

Al respecto cabe señalar que si se analiza la cuestión de manera más profunda se advierte que el hecho de tener que cancelar este tributo implica sin duda un gasto para el agente contaminador, lo cual sin duda repercutirá de alguna manera en las finanzas del mismo, puesto que este pago extra, incidirá por ejemplo en el incremento del valor del producto, lo cual lo volvería menos competitivo en el mercado. Sin embargo, para que el tributo surta el efecto deseado, sin dejar de considerar todos los principios que rigen en materia tributaria, en especial el principio de proporcionalidad, es necesario que la cuantía de los mismos sea elevada.

La segunda objeción que ha recibido la aplicación de los tributos ambientales está relacionada con la parte financiera, puesto que en principio los tributos pigouvianos, si cumplen con su función de manera ideal, no allegarían recursos al estado, puesto que la recaudación debería ser nula ya que la actividad contaminante quedaría eliminada, con lo 
cual se desnaturalizaría también esta institución, ya que como se ha mencionado, al menos su fin secundario debe ser obtener ingresos para el Estado, los cuales en opinión de la autora, con la finalidad de que el ciclo se cierre completamente deberían ser destinados al menos en parte para resarcir el daño causado al medio ambiente.

En relación a este punto se debe mencionar que aplicar tributos ambientales cuando se pretende disminuir no eliminar con una conducta contaminante, pues en el segundo caso cabrían de mejor manera las sanciones.

Lo mencionado se reafirma con lo que expresa Arnaldo (2007), quien menciona algunas razones para que en la práctica se debe esperar un ingreso superior a cero como producto de la aplicación de los tributos ambientales y que son las siguientes:

1. Para la mayoría de los problemas ambientales parece difícil desde el punto de vista tanto económico como ambiental, reducir las emisiones en su totalidad. Bajo un punto de vista ambiental es difícil que el ambiente tenga la suficiente capacidad para absorber las sustancias contaminantes (por lo menos en el estado actual) y bajo el punto de vista económico, es difícil (por los costos) llegar a una emisión cero. Así, en el caso de los impuestos pigouvianos, el remanente de emisión es imposible, lo que se traduce en ingresos tributarios.

2. Considerando el crecimiento económico, los elementos que deberán ser manejados por las políticas, se espera que aumenten en el futuro. Si los impuestos se constituyen en parte de las políticas, deberá esperarse una mayor recaudación.

3. En alguna área, productos o actividad p.ej. pesticidas no hay muchas oportunidades para aplicar una política blanda. Aquí debe usarse el impuesto pigouviano. Sin embargo, se verá que en este caso extremo es posible que sea más efectiva la prohibición del producto. Cuando se introduce un impuesto pigouviano, es posible esperar un ingreso fiscal mayor a cero, debido a que lleva tiempo para que los enfrentados al impuesto cambien de conducta. Por lo tanto, al inicio hasta que los contaminadores se adapten a la nueva situación, la implementación de los impuestos pigouvianos tendrá efectos fiscales (el contaminado preferirá pagar el impuesto antes que bajar la emisión. (pp.35 y 36) 


\section{¿Por qué utilizar tributos ambientales como instrumentos de política pública para proteger el derecho -deber a un medio ambiente sano en el Ecuador?}

Con base en lo mencionado se señala a continuación las principales razones por las cuales en nuestra opinión deben utilizarse los tributos como mecanismos de política pública para preservar el medio ambiente en nuestro país.

La primera y fundamental razón surge de la base de este estudio; y, está relacionada con el hecho de que, en el caso ecuatoriano, como se ha evidenciado existen varias políticas públicas, quizá las más importantes, que a más de utilizarse para solventar los problemas públicos tienen dentro de sus objetivos preservar el medio ambiente, para lo cual los tributos son sumamente eficaces y aplicables. Agregando, a los mencionados que estas políticas públicas son en nuestro país auténticas garantías constitucionales, y por lo tanto instrumentos para lograr la plena efectividad de los derechos constitucionales, es una obligación del Estado considerarlas como uno de los medios con los que cuenta para proteger este bien tan preciado.

Ligado a lo anterior, de lo examinado, se puede señalar como otro punto a favor de la aplicación de tributos como instrumentos de política pública para proteger el medio ambiente en nuestro país, que el marco jurídico no solamente lo permite, sino que lo fomenta, al establecer varias disposiciones al respecto en nuestro texto constitucional.

El tercer motivo para la utilización de esta institución como mecanismo de política pública para proteger el ambiente, es que los tributos son mecanismos muy útiles para la internalización de externalidades, es decir, para que el costo que genera la contaminación sea asumido por el agente contaminador, lo cual se debe principalmente a que son instrumentos de carácter económico.

Se debe agregar como otro argumento a favor de la utilización de este instituto como medio de protección del ambiente dentro de las políticas públicas, el hecho de que, si bien en este trabajo se remite a la utilización específica de tributos en cualquiera de sus tres especies, 
la tributación es mucho más amplia, pues cabe la utilización de otras instituciones como exenciones, beneficios, incentivos, etc., de carácter tributario, con la finalidad de preservar el medio ambiente.

La siguiente razón está relacionada con la necesidad de que en la actualidad a nivel mundial se pretenda un desarrollo sostenible, en el sentido de que, si bien no puede destruirse por completo el medio ambiente con la finalidad de cumplir con ciertas actividades, tampoco es posible terminar con el desarrollo económico de los países, lo cual siempre va a implicar cierto grado de contaminación. En este caso los tributos ambientales son los instrumentos más idóneos, ya que como lo se señaló anteriormente, debe aplicárselos cuando lo que se pretende es disminuir determinada actividad contaminante, no eliminarla por completo, en cuyo caso caben las sanciones.

Otra motivación para usar tributos como mecanismos para proteger el medio ambiente dentro de las políticas públicas, es que los mismos a la vez de disuadir las conductas contaminantes van a llegar recursos al Estado, por ciertas razones como por ejemplo el que no es fácil acoger las políticas establecidas, ya que esto implica costos y tiempo.

Entonces, se finaliza este punto señalado, que la tributación ambiental es un mecanismo sumamente eficiente para ser utilizado en algunas políticas públicas en el Ecuador con la finalidad de alcanzar, entre otros objetivos, la plena eficacia del derecho - deber constitucional a un medio ambiente sano.

\section{CONCLUSIONES}

Debido al crecimiento del intervencionismo del Estado, a partir de la Constitución del Ecuador 2008; y, al incremento de la complejidad de los problemas públicos no debe resultar extraño que el Estado haga uso del sistema tributario para llevar adelante ciertas políticas públicas. 
Las Políticas Públicas en el Ecuador son auténticas garantías de carácter constitucional, por lo tanto, mecanismos para lograr la plena efectividad de los derechos de carácter constitucional, como lo es el derecho a un medio ambiente sano.

El fin extra fiscal de los tributos ha sido aceptado de modo general por la doctrina, y en el caso del Ecuador se ha establecido específicamente en la normativa, por lo que pueden ser utilizados como instrumentos de protección ambiental.

Tributos medioambientales son aquellos impuestos, tasas y contribuciones especiales cuyo objeto imponible esté constituido por actos o hechos que inciden negativamente sobre el medio ambiente o que provocan una actuación pública de tutela medioambiental.

Los instrumentos económico - fiscales, entre estos los tributos han demostrado su eficacia a nivel mundial como mecanismos de protección ambiental.

\section{REFERENCIAS BIBLIOGRÁFICAS}

Aizega,J (2001). La utilización extrafiscal de los impuestos y los principios de justicia tributaria. Bilbao: Servicio editorial de la Universidad del País Vasco.

Amaya O. (2010). La Constitución Ecológica de Colombia, Colombia: Universidad Externado de Colombia

Arnaldo R. (2007). Impuestos Ambientales. Buenos Aires: OSMAR.

Asamblea Constituyente 2008, Constitución de la República del Ecuador 2008, Registro Oficial 449 de 20 -oct-2008.

Ávila Santamaría, Ramiro. (2008) "Las garantías: herramientas imprescindibles para el cumplimiento de los derecho. Avances conceptuales en la Constitución del 2008.", en Desafíos constitucionales La Constitución ecuatoriana del 2008 en perspectiva. Quito: Quito, Ministerio de Justicia y Derechos Humanos / Tribunal Constitucional del Ecuador.

Barbe, L. (1996). El curso de economía. España: Ariel S.A.

Bustamante, C. (2013). Nueva Justicia Constitucional. Neoconstitucionalismo Derechos y Garantías. Teoría y Práctica. Quito: Editorial Jurídica del Ecuador. 
Callisaya F. (2012). Manual de Derecho Ambiental, La Paz: Producciones Cima Editores.

Cámara, M. (2014). La armonización del impuesto sobre hidrocarburos en la Unión Europea. Madrid: DYNKINSON.

De La Garza S. (2008) Derecho Financiero Mexicano. México: Porrúa.

Días, V. (Ed.). (2004). Tratado de tributación política y economía tributaria. Buenos Aires: ASTREA.

Fernández, A. (2001). Manual de Ciencia Política. Madrid: EDITORIAL TECNOS.

Figueroa, A. (2000). Fiscalidad y Medio Ambiente en México. México: Porrua.

Ferrajoli, L. (2006). Garantismo una discusión sobre derecho y democracia. Madrid: Trotta.

Fonseca, C. (2010). Manual de Derecho Ambiental, Perú: Adrus.

Gago A. y otros, (2008) Imposición ambiental y reforma fiscal verde: tendencias recientes y análisis de propuestas Vigo, Universidad de Vigo.

García C. (2010). El concepto de tributo. España: Tax Editor.

Giuliani, C. (1984). Derecho Financiero. Buenos Aires: Depalma.

González, J.D. y otros. (2013). Curso de derecho internacional público. Madrid: Porrua.

González, E. (2008). Estudios en Homenaje al Profesor Pérez de Ayala. Madrid:

Dykinson,

Granados, G. (2015). Manual de Derecho Tributario. México: Porrúa.

Instituto de Estudios Fiscales. (2003). Modelo de Código Tributario Ambiental para América Latina (Doc. 18/03/). Recuperado de http://www.ief.es/documentos/recursos/publicaciones/documentos_trabajo/2 003_18.pdf

Jaramillo V. (2011). Las Garantías Jurisdiccionales en el Sistema Jurídico Ecuatoriano, Quito, Corporación de Estudios y Publicaciones. 
Mármol, E. (2003). Principios de Economía Política Mundial la ONU y sus Políticas de ambiente. Guayaquil- Ecuador: Servicios Gráficos Alcívar.

Merino M. (2011) Fines extrafiscales sus límites constitucionales. México: Porrúa.

OECD. (1991). Recommendation of the Council on the Use of Economic Instruments in Environmental Policy. Recuperado de http://acts.oecd.org/Instruments/ShowlnstrumentView.aspx? InstrumentID=4 $1 \&$ Lang=en\&Book=False

Oliva, N. (2011). Impuestos Verdes: ¿una alternativa viable para el Ecuador? Quito: Centro de Estudios Fiscales.

ONU (1992). Declaración de Rio sobre el Medio Ambiente y el Desarrollo.

Ordóñez, G. (2013). Manual de análisis y diseño de políticas pública., Bogotá: Universidad Externado de Colombia.

Pérez, F. (2010). Derecho Financiero y Tributario Parte General. España: CIVITAS.

Plazas, M. (2006). Derecho de la Hacienda Pública y Derecho Tributario. BogotáColombia:TEMIS..S.A.

Plazas, M. (2010). Derecho Tributario Comunitario. La armonización tributaria en el Sistema Andino de Integración. Santa Fe de Bogotá: Legis.

Palos, M. (2012) El tributo ambiental local, México, UNAM: 2012.

Queralt, J. (2000). Derecho Tributario. España: ARAZANDI S.A.

Rojo, R. y Flores R. (2013) Manual de derecho internacional ambiental. Bolivia: Impresiones Gráficas, 2013

Storini, C. Las Garantías Constitucionales de los Derechos Fundamentales en la Constitución Ecuatoriana de 2008. En S. Andrade, A. Grijalva y C. Storini. (Eds.), La nueva Constitución del Ecuador Estado, Derechos e Instituciones, (pp. 287- 300). Quito : Corporación Editora Nacional.

Valdivieso, G. (2013). La tasa, un tributo que ha sido desnaturalizado en Ecuador. Quito: Corporación Editora Nacional.

Valdivieso, G, (2016). El impuesto como mecanismo de garantía constitucional del derecho a un medio ambiente sano en el Ecuador. Universidad Andina Simón Bolívar, Quito, Ecuador. 
Vicuña, L. (mayo de 2015). La política económica y sus efectos. El Telégrafo. Recuperado de http://www.eltelegrafo.com.ec/noticias/columnistas/1/la-politicaeconomica-y-sus-efectos-i 